\title{
Pneumococcal serotype evolution in Western Europe
}

\author{
Myint Tin Tin Htar*, Dina Christopoulou and Heinz-Josef Schmitt
}

\begin{abstract}
Background: Pneumococcal diseases remain a leading cause of vaccine-preventable death worldwide in children $<5$ years of age. The seven-valent pneumococcal conjugate vaccine (PCV7) was approved in 2001 in Europe and was introduced into the national immunization programmes of many European countries from 2006-2008. In 2009, higher-valent PCVs (PCV10 and PCV13) became available, replacing PCV7 from 2009-2011. This article describes the evolution of vaccine and non-vaccine serotypes causing invasive pneumococcal disease (IPD) following the introduction of PCVs in Western Europe, based on data from publicly-available medical publications and national surveillance systems from January 2010 to May 2015.

Discussion: In countries with high vaccine uptake, 5-7 years after PCV7 introduction IPD caused by vaccine serotypes has almost disappeared in children. Non-PCV7 serotypes have emerged, particularly serotypes 19A, 7 F, 3 and 1. A rapid and significant reduction of the additional serotypes included in higher-valent vaccines has been observed consistently following the introduction of these vaccines. A significant and rapid decline of serotypes 19A, 7 F, 1 and 6A in both vaccine-eligible and older age groups has been observed in countries using PCV13 while serotype 19A and 3 has increased in countries using PCV10. Serotype 3 has become one of the most prevalent serotypes in adults, with some reduction only in the UK and France. Serotype diversity increased and varied by age group, the type of vaccine in use, and the time since the introduction of higher-valent PCVs. Serotypes that are currently more frequent include 24 F, 22 F, 8 and 15A in countries that use PCV13, and serotypes 19A and 3 in countries that use PCV10. Compared with the time before the introduction of higher valent PCVs, to date, there is no single '19A-like' serotype emerging across countries and most of the newly emerging non-PCV13 vaccine types are less invasive with a low case-carrier ratio.

Conclusions: It is important to closely monitor not only evolving serotypes but also the magnitude of the effect in order to evaluate the overall impact of pneumococcal vaccination programmes and to initiate the appropriate vaccination strategy. Emerging serotypes may also need to be considered for the future development of new vaccines.
\end{abstract}

Keywords: Invasive pneumococcal diseases, Pneumococcal serotype, Pneumococcal conjugate vaccines

\section{Background}

Pneumococcal diseases remain a leading cause of vaccinepreventable death worldwide in children $<5$ years of age [1]. The first pneumococcal conjugate vaccine (PCV7) comprising serotypes $4,6 \mathrm{~B}, 9 \mathrm{~V}, 14,18 \mathrm{C}, 19 \mathrm{~F}$, and $23 \mathrm{~F}$ was licensed in 2001 in Europe for the prevention of pneumococcal disease in children. It was introduced into the national immunization programmes (NIPs) of many European countries between 2006 and

\footnotetext{
* Correspondence: Myint.TinTinHtar@pfizer.com

Pfizer Vaccines, Medical Development Group and Scientific Affairs, 23-25 avenue du Dr. Lannelongue, F-75668 Paris, Cedex 14, France
}

2008. In 2009, higher-valent PCVs became available: PCV10 (including additional serotypes 1,5 and $7 \mathrm{~F}$ ) and, later PCV13 (including additional serotypes 1, 3, 5, 6A, $7 \mathrm{~F}$ and 19A) [2]. These vaccines usually replaced PCV7 between 2009 and 2011.

PCV immunization has been successful in decreasing the mortality and morbidity associated with invasive and mucosal pneumococcal diseases caused by vaccine serotypes in children [3-8]. A reduction in nasopharyngeal carriage of vaccine serotypes has also led to a substantial herd effect (indirect protection) in the older population [9]. Following the introduction of PCV7, a marked 
reduction in diseases related to vaccine serotypes has been observed alongside the emergence of non-vaccine serotypes $[6,10]$. This article describes the evolution of vaccine and non-vaccine serotypes causing invasive pneumococcal disease (IPD) following the introduction of PCVs in Western Europe.

Data are included from national surveillance systems as well as representative observational studies available within Medline publications and national surveillance websites from January 2010 to May 2015 in 15 Western European countries: Austria, Belgium, Denmark, Finland, France, Germany, Ireland, Italy, The Netherlands, Norway, Portugal, Spain, Sweden, Switzerland and the UK. Singlecentred observational studies or clinical trials were not considered for this review. Only data from original articles were considered.

\section{Discussion}

\section{Countries in which only PCV13 is used Belgium}

PCV7 was introduced into the NIP in January 2007 with a $2+1$ schedule and was replaced by PCV13 in July 2011 . By 2012, the vaccination coverage was estimated at $98 \%$ for the first dose and $93 \%$ for the third dose [11].

After 4 years of implementation of PCV7 into the NIP followed by 2 years of implementation of PCV13, the overall incidence of IPD in children $<2$ years of age decreased continuously from 155.9 to $56.0 / 100,000$ population between 2002-2003 and 2013, respectively (Table 1). The incidence also decreased in those 2-5 years of age but remained the same in those 5-15 years of age.

In 2010, following the decrease in PCV7-serotype IPD, non-vaccine-type IPD emerged. At this time, PCV13 serotypes accounted for $73 \%$ of all IPD cases and the most prevalent serotypes were 19A, 1 and 7 F (60\% of all IPD cases). In 2013, PCV13 serotypes accounted for $36 \%$ of IPD cases and serotypes 19A, 1 and $7 \mathrm{~F}$ accounted for $29 \%$ of all IPD cases. Serotypes $12 \mathrm{~F}$ and $24 \mathrm{~F}$ became more prevalent, representing 12 and $7 \%$ of all IPD cases, respectively. Serotype 3 was not observed in children <5 years of age in 2013 (Table 2) [11]. In 2010, PCV7 serotypes decreased significantly among individuals $\geq 60$ years of age, and non-PCV7 serotypes (e.g., $38,7,12$ and 22) increased [12].

\section{Denmark}

PCV7 was introduced into the NIP with a $2+1$ schedule in October 2007. It was replaced by PCV13 in April 2010 with a two-dose catch-up for children 12-17 months of age. Vaccine coverage for one dose of PCV13 was $92 \%$ in 2011 [13].

In children $<2$ years of age, the incidence of PCV7serotype IPD was significantly reduced from 36.4/100,000 population in $2000-2007$ to $3.9 / 100,000$ population in
Table 1 Incidence of IPD (/100,000 population) in Western European countries

\begin{tabular}{|c|c|c|c|}
\hline & Pre-PCV7 period & Post-PCV7 period & $\begin{array}{l}\text { Post-higher } \\
\text { PCV period }\end{array}$ \\
\hline \multicolumn{4}{|c|}{ Countries in which only PCV13 used } \\
\hline Belgium [11] & 2002-2003 & & 2013 \\
\hline$<2$ years & 155.9 & & 56.0 \\
\hline Denmark [14] & $2000-2007$ & 2008-2010 & $2011-2013$ \\
\hline$<2$ years & 55.1 & 25.9 & 16.0 \\
\hline$\geq 65$ years & 65.5 & 60.0 & 49.4 \\
\hline France [20] & $2001-2002$ & 2008-2009 & 2012 \\
\hline$<2$ years & 30.3 & 24.6 & 17.2 \\
\hline$>64$ years & 27.7 & 31.1 & 26.5 \\
\hline Ireland [21] & 2008 & 2011 & 2012 \\
\hline All ages & 9.5 & 7.6 & 7.6 \\
\hline Norway [25] & 2005 & 2010 & 2012 \\
\hline$<2$ years & 77.0 & 20.0 & 8.1 \\
\hline All ages & 23.0 & 15.0 & 13.0 \\
\hline Spain (Madrid) [27] & - & $2007-2010$ & 2011-2012 \\
\hline$<15$ years & - & 17.1 & 7.7 \\
\hline Switzerland $[29,30]$ & $2002-2005$ & 2010 & 2012 \\
\hline$<2$ years & 27.1 & 20.6 & 8.1 \\
\hline$\geq 65$ years & 42.1 & 35.2 & 35.7 \\
\hline UK [31] & & $2008-2010$ & 2013-2014 \\
\hline$<2$ years & - & 22.2 & 12.0 \\
\hline$\geq 65$ years & - & 27.6 & 20.6 \\
\hline \multicolumn{4}{|c|}{ Countries in which only PCV13 used } \\
\hline Finland [39] & 2006 & 2010 & 2014 \\
\hline$<1$ year & 68.5 & 50.7 & 11.2 \\
\hline$>64$ years & 31.1 & 32.3 & 32.5 \\
\hline \multicolumn{4}{|c|}{ Countries in which both PCV13 and PCV10 used } \\
\hline Germany [42-44] & 1997-2001 & 2010 & 2012 \\
\hline$<2$ years $^{a}$ & 7.7 & 4.1 & 3.7 \\
\hline$<2$ years $^{\mathrm{b}}$ & 12.7 & 9.4 & 6.3 \\
\hline Spain (Navarra) [47] & 2001-2003 & 2004-2009 & 2010-2013 \\
\hline$<5$ years & 87.1 & 60.7 & 18.7 \\
\hline$\geq 65$ years & 33.6 & 32.5 & 25.0 \\
\hline Portugal [48] & & 2008-2009 & 2011-2012 \\
\hline$<1$ year & - & 52.1 & 25.1 \\
\hline $1-2$ years & - & 31.6 & 16.1 \\
\hline
\end{tabular}

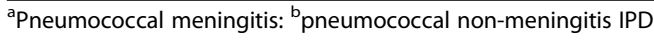

2008-2010 and to $0.3 / 100,000$ population in 2011-2013, with only one case caused by $19 \mathrm{~F}$ in 2011 . The overall IPD was reduced from 55.1/100,000 population to 16.0 / 100,000 population from 2000-2007 to 2011-2013 (Table 1) [14]. In children $<3$ months of age, PCV7serotype disease has not been detected since 2010 [15]. 
Table 2 Prevalence of PCV13 serotypes in Western European countries in children $<5$ years of age. For details on local vaccine use, please see text

\begin{tabular}{|c|c|c|c|c|c|c|c|}
\hline & \multirow[t]{2}{*}{ Age (year) } & \multicolumn{2}{|c|}{ Post-PCV7 period } & \multirow{2}{*}{$\begin{array}{l}\text { Three most } \\
\text { prevalent } \\
\text { serotypes }\end{array}$} & \multicolumn{2}{|c|}{ Post-higher valent PCV periods } & \multirow{2}{*}{$\begin{array}{l}\text { Three most } \\
\text { prevalent serotypes }\end{array}$} \\
\hline & & Year & Among all IPD, \% & & Year & Among all IPD, \% & \\
\hline \multicolumn{8}{|c|}{ Countries in which only PCV13 used } \\
\hline Belgium [11] & $<5$ & 2010 & 73 & $19 \mathrm{~A}, 1,7 \mathrm{~F}$ & 2013 & 36 & $1,12 F, 24 F$ \\
\hline France [20] & $<2$ & 2009 & 71 & $19 A, 7 F, 1$ & 2012 & 24 & $24 F, 12 F, 15 B / C$ \\
\hline Italy [24] & $<5$ & 2011 & 64 & $1,19 \mathrm{~A}, 22 \mathrm{~F}$ & 2014 & 37 & $19 \mathrm{~A}, 1,24 \mathrm{~F}$ \\
\hline Norway [25] & $<5$ & 2010 & 61 & $19 \mathrm{~A}, 1,7 \mathrm{~F}$ & 2012 & 26 & $1,15 B / C$ \\
\hline Switzerland [29] & $<2$ & 2010-2011 & 68 & $3,19 \mathrm{~A}, 7 \mathrm{~F}$ & 2012 & 53 & $3,23($ not $23 \mathrm{~F}), 19 \mathrm{~F}$ \\
\hline UK [31] & $<5$ & 2008-2010 & 68 & $7 \mathrm{~F}, 19 \mathrm{~A}, 1$ & 2013-2014 & 15 & $24 F, 22 F, 33 F$ \\
\hline \multicolumn{8}{|c|}{ Countries in which only PCV10 used } \\
\hline Austria $[33,37]$ & $<5$ & 2009 & 73 & $3,14,18 \mathrm{C}$ & 2013 & 93 & $19 A, 7 F, 23 F$ \\
\hline Finland [39] & $<5$ & 2010 & 92 & $14,6 \mathrm{~B}, 19 \mathrm{~F}$ & 2014 & 70 & $19 A, 3,7 F, 23 A$ \\
\hline \multicolumn{8}{|c|}{ Countries in which both PCV13 and PCV10 used } \\
\hline Germany $^{\mathrm{a}}[44]$ & $<16$ & 2008-2009 & 56 & $7 F, 1,18 C^{b}$ & 2012-2013 & 12 & $7 F, 10 A, 19 A^{C}$ \\
\hline Sweden [45] & $<2$ & 2009 & 84 & $22 F, 7 F, 3,19 A$ & 2012 & 47 & $33 F, 11$ \\
\hline
\end{tabular}

apneumococcal meningitis; ${ }^{\mathrm{b}} 2007-2010 ;{ }^{\mathrm{c}} 2010-2013$

In adults $\geq 65$ years of age, a similar reduction was also observed for overall IPD and PCV7-serotype IPD. The incidence of PCV7-serotype IPD significantly decreased from 27.1/100,000 population in 2000-2007 to 3.3/ 100,000 population in 2011-2013 [14].

In 2008-2010, the most prevalent serotypes were 1, $7 \mathrm{~F}$ and $19 \mathrm{~A}$ in children $<5$ years of age and $1,7 \mathrm{~F}$ and 3 in those $\geq 65$ years of age [14, 16, 17]. In 2013, serotype 19A significantly increased in all ages following the introduction of PCV7 but significantly decreased following PCV13 introduction (zero cases in children $<2$ years of age). Incidence of serotypes 1 and 3 showed no significant changes beyond the expected natural cyclical variations. Non-PCV13 serotypes accounted for nearly $80 \%$ of cases with no clear predominance of a specific serotype in 2011-2013 [14].

\section{France}

PCV7 was introduced into the NIP in June 2006 with $2+1$ schedule, and was replaced by PCV13 in June 2010 [18]. Vaccine coverage was $94 \%$ in 2009 and remained high in 2012 [19].

Following the introduction of PCV7, the overall incidence of IPD gradually reduced in children $<2$ years of age from $30.3 / 100,000$ population in $2001-2002$, to $24.6 / 100,000$ population in 2008-2009 and 17.2/ 100,000 population in 2012 . In adults $>64$ years of age, the incidence increased after the introduction of PCV7 from 27.7 to $31.1 / 100,000$ population (2001-2002 to 2008-2009, respectively), then decreased in 2012 to 26.5/100,000 population, similar to the incidence before the introduction of PCVs (Table 1).
The incidence of PCV7 serotypes significantly declined following the introduction of PCV7, and in 2012, PCV7 serotypes accounted for $6 \%$ of all IPD cases in children $<2$ years of age and $8 \%$ of cases in adults $\geq 50$ years of age. In 2009, PCV13 serotypes accounted for $71 \%$ of all IPD cases in children $<2$ years of age, which subsequently declined to $24 \%$ in 2012 (Table 2), mainly due to a significant reduction in serotypes 19A (83\% reduction), 7 F (77 \% reduction), 1 (96\% reduction) and 3 ( $85 \%$ reduction). The incidence of non-PCV13 serotypes $24 \mathrm{~F}$ and $12 \mathrm{~F}$ increased, accounting for 20 and $10 \%$ of all IPD cases, respectively. In adults $>65$ years of age, despite a significant decrease, PCV13 serotypes remained prevalent (42\% of all IPD cases) with 19A, 3 and $7 \mathrm{~F}$ predominating (Table 3) $[18,20]$.

\section{Ireland}

PCV7 was introduced into the NIP in September 2008 with a $2+1$ schedule and was replaced by PCV13 in December 2010. Vaccine coverage was $91 \%$ in 2012 for three doses in children $<2$ years of age [21].

The overall incidence of IPD in general population decreased from 9.5/100,00 population in 2008 to $7.6 /$ 100,000 population in 2011 and remained the same in 2012 (Table 1). In 2008, serotype 14 was the most predominant serotype followed by $4,9 \mathrm{~V}, 7 \mathrm{~F}, 8,23 \mathrm{~F}$ and $6 \mathrm{~B}$. These serotypes combined accounted for approximately $53 \%$ of all IPD cases within the population. In 2010, PCV7-serotype IPD declined by $91 \%$ compared with 2008 in children $<2$ years of age and by $50 \%$ in those $>2$ years of age. PCV13 serotypes accounted for 
Table 3 Prevalence of PCV13 serotypes in Western European countries in older populations

\begin{tabular}{|c|c|c|c|c|c|c|c|}
\hline & \multirow[t]{2}{*}{ Age (year) } & \multicolumn{2}{|c|}{ Post-PCV7 period } & \multirow{2}{*}{$\begin{array}{l}\text { Three most } \\
\text { prevalent } \\
\text { serotypes }\end{array}$} & \multicolumn{2}{|c|}{ Post-higher valent PCV periods } & \multirow{2}{*}{$\begin{array}{l}\text { Three most } \\
\text { prevalent } \\
\text { serotypes }\end{array}$} \\
\hline & & Year & Among all IPD, \% & & Year & Among all IPD, \% & \\
\hline \multicolumn{8}{|c|}{ Countries in which only PCV13 used } \\
\hline France $[18,20]$ & $\geq 65$ & 2009 & 61 & $19 \mathrm{~A}, 7 \mathrm{~F}, 3^{\mathrm{a}}$ & 2012 & 42 & $19 \mathrm{~A}, 3,7 \mathrm{~F}^{\mathrm{a}}$ \\
\hline Norway [25] & $>5$ & 2010 & 52 & $7 F, 19 A, 1,3$ & 2012 & 45 & $7 F, 19 A, 3$ \\
\hline Switzerland [29] & $>64$ & 2010-11 & 66 & $3,19 \mathrm{~A}, 7 \mathrm{~F}$ & 2012 & 62 & $3,19 \mathrm{~A}, 7 \mathrm{~F}$ \\
\hline UK [31] & $\geq 65$ & $2008-10$ & 54 & $19 \mathrm{~A}, 3,22 \mathrm{~F}$ & $2013-14$ & 21 & $8,22 F, 3$ \\
\hline \multicolumn{8}{|c|}{ Countries in which only PCV10 used } \\
\hline Austria $[33,37]$ & $>50$ & 2009 & 69 & $3,6 \mathrm{~A}, 14$ & 2013 & 59 & $3,14,19 \mathrm{~A}$ \\
\hline Finland [39] & $>65$ & 2010 & 72 & $14,3,23 \mathrm{~F}$ & 2014 & 60 & $3,22 \mathrm{~F}, 19 \mathrm{~A}$ \\
\hline Netherlands [41] & All ages & 2010 & 60 & $7 \mathrm{~F}, 8,19 \mathrm{~A}, 1$ & 2013 & 45 & $8,7 \mathrm{~F}, 19 \mathrm{~A}$ \\
\hline \multicolumn{8}{|c|}{ Countries in which both PCV13 and PCV10 used } \\
\hline Germany $^{\mathrm{a}}[42,44]$ & $>16$ & $2008-2009$ & 56 & $3,7 F, 22 F^{b}$ & $2012-2013$ & 25 & $23 \mathrm{~B}, 3,7 \mathrm{~F}^{\mathrm{C}}$ \\
\hline
\end{tabular}

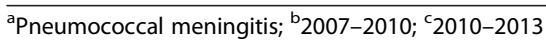

$55 \%$ of all IPD cases in all ages at the time PCV13 was introduced. In 2014, the predominant serotypes were $7 \mathrm{~F}, 15 \mathrm{~A}, 22 \mathrm{~F}$ in all ages $[21,22]$.

\section{Italy}

PCV7 was introduced into immunization programme in May 2005 as a $2+1$ schedule and it was replaced by PCV13 in the summer of 2010. Vaccine coverage differed between regions and was 50-60 \% between 2005 and 2007 [23]. The number of IPD cases reported to the national laboratory surveillance centre was generally low but did decrease. In 2005, PCV7 serotypes accounted for $50 \%$ of all IPD cases in children 0-4 years of age, declining to $31 \%$ of cases in 2007 and $19 \%$ of cases in 2011 (one case each for 23 and 19 F). In 2011, PCV13 serotypes accounted for $64 \%$ of all IPD cases, which declined to $37 \%$ in 2014 (Table 2). Between 2007 and 2009, twothirds of pneumococcal bacteraemia cases in children were due to non-PCV7 serotypes; serotype 1 was the most frequent and was associated with complications, followed by serotype 19A, which was associated with younger age. Serotypes 19A and 1 were the most prevalent in 2011 and remained high in 2014 [24].

\section{Norway}

PCV7 was included into the NIP with a $2+1$ schedule in July 2006, with a catch-up campaign for children born in 2006 only, and was replaced by PCV13 in April 2011. Vaccine coverage was $92 \%$ for children born from 2009 onwards [25].

The incidence of overall IPD decreased gradually from $23 / 100,000$ population in 2005 to $15 / 100,000$ population in 2010 and 13/100,000 population in 2012, one year after PCV13 introduction (Table 1). The largest decrease was observed for PCV7-serotype IPD, particularly in children $<2$ years of age (incidence of 64/100,000 population in 2005 and zero in 2012). A similar decrease in other age groups (2-4 years, 50-64 years and $\geq 65$ years) was also observed [25].

In 2005, PCV7 serotypes accounted for about $63 \%$ of all IPD cases in children $<5$ years of age. In 2010 , with the virtual elimination of all PCV7 serotypes (one case of $19 \mathrm{~F}$ reported), PCV13 serotypes comprised $61 \%$ of IPD cases; serotypes $19 \mathrm{~A}, 1$ and $7 \mathrm{~F}$ were the most prevalent. In 2012, PCV13 serotypes still accounted for $26 \%$ of all IPD cases although no cases of PCV13-serotype IPD were observed in children $<2$ years of age (Table 2). In those $>5$ years of age, PCV7 serotypes comprised $53 \%$ of IPD cases in 2005, which gradually declined to $8 \%$ in 2012. PCV13 serotypes accounted for $52 \%$ of all IPD cases in 2010, decreasing to $45 \%$ in 2012 (Table 3). Since 2010, IPD due to serotypes $23 \mathrm{~B}$ and $15 \mathrm{~A}$ increased. The number of cases caused by serotype 1 fluctuated between 1994 and 2002, became stable and then declined in all ages after the introduction of PCV13. In adults $\geq 65$ years of age, a decrease in all PCV13 serotypes was observed with the exception of serotype 3 [25].

\section{Spain (Madrid region)}

PCV7 became available in 2001 and was incorporated into the regional immunization programme in Madrid in November 2006 with a $2+1$ schedule and PCV13 was replaced in June 2010. Vaccine coverage was $>90 \%$ in the Madrid region [26].

In children $<15$ years of age, the incidence of IPD was significantly reduced from $17.1 / 100,000$ population in 2007-2010 to 7.7/100,000 population in 2011-2012 (Table 1). In 2007-2009, non-PCV7 serotypes, such as 1, 19A, 5, $7 \mathrm{~F}$ and 3, became more prevalent. A significant reduction of PCV13 serotypes 1 and 19A was observed following PCV13 introduction in 2010 [27]. No cases of serotype $19 \mathrm{~A}$ were observed in children $<5$ years of age in 
2013. No significant change in the number of serotype 3 cases was observed, but there was an increase in serotype 8 cases. In 2013, serotypes 8, 3 and 19A were the most prevalent in the general population [26-28].

\section{Switzerland}

PCV7 was introduced into the NIP in November 2005 with a $2+1$ schedule and was replaced by PCV13 in 2011 . Vaccine coverage was around $76 \%$ in 2012 with $\geq 2$ doses in children $<2$ years of age [29].

From 2002-2005 to 2012, the overall IPD incidence decreased from 12.6 to $10.9 / 100,000$ population. The most important decrease was in children $<2$ years of age, from 27.1 to $8.1 / 100,000$ population. In adults $>64$ years of age, the decrease in IPD incidence was moderate and remained relatively high (42.1/100,000 population in 2002-2005 and $35.7 / 100,000$ population in 2012) (Table 1) [29, 30]. In children $<2$ years of age, PCV7 serotypes accounted for $66 \%$ of all IPD cases in 2004, which reduced to $17 \%$ in 2010-2011 with the emergence of non-PCV7 serotypes, such as 3, 19A and 7 F. PCV13 serotypes comprised $68 \%$ of IPD cases in 2010-2011, declining to $53 \%$ in 2012, one year after PCV13 introduction. Serotypes 3 and 23 (not $23 \mathrm{~F}$ ) remained the most prevalent serotypes in children, followed by $19 \mathrm{~F}$ (Table 2 ). In adults $>64$ years of age, PCV13 serotypes accounted for $66 \%$ of all IPD cases in 2010-2011 and $62 \%$ of cases in 2012. Serotypes $3,19 \mathrm{~A}$ and $7 \mathrm{~F}$ were the most prevalent in 2010-2012 (Table 3) [29, 30].

\section{United Kingdom}

PCV7 was introduced into the NIP in September 2006 with a $2+1$ schedule and was replaced by PCV13 in April 2010. Vaccine coverage was $>90 \%$ in 2012-2013 [31].

The overall incidence of IPD significantly declined in all ages following PCV7 introduction in 2006 and PCV13 in 2010. From 2008-2010 to 2013-2014, the IPD incidence decreased from 22.2 to $12 / 100,000$ population in children $<2$ years of age and from 27.6 to 20.6/ 100,000 population in adults $>64$ years of age (Table 1 ). In 2008-2010, non-PCV7 serotypes became prevalent, notably 7 F, 19A and 1 in children $<5$ years of age and 19A, 3 and $22 \mathrm{~F}$ in adults $\geq 65$ years of age (Tables 1 and 2). The incidence of PCV7-serotype IPD reached near-extinction in 2013-2014 (0.20/100,000 population). Serotypes 6A/6C also significantly decreased in children $<5$ years of age.

Four years after the introduction of PCV13, the proportion of PCV13 serotypes decreased from $68 \%$ (2008-2010) to $15 \%(2013-2014)$ in children $<5$ years of age and from $54 \%(2008-2010)$ to $21 \%$ (2013-2014) in adults $\geq 65$ years of age (Table 2). Serotypes 19A, 1, 7 F, 3 and 6A were significantly reduced, although yearon-year fluctuations were observed for serotype 3 .
Serotype 3 significantly decreased (44\% reduction) but remained prevalent in adults $\geq 65$ years of age. Serotype 5 , which is an outbreak strain, has not been detected in recent years. Non-vaccine serotypes generally increased in all ages and significantly in those $>50$ years of age. The most common serotypes were $24 \mathrm{~F}, 22 \mathrm{~F}$ and $33 \mathrm{~F}$ in children $<5$ years of age and $8,22 \mathrm{~F}$ and 3 in adults $\geq 65$ years of age (Tables 2 and 3 ) [10,31].

\section{Countries in which only PCV10 is used Austria}

In 2012, PCV10 was the first PCV introduced into NIP with a $2+1$ schedule. Vaccine coverage in 2012 was over $90 \%$ [32].

Annually, about 200 to 330 IPD cases were reported to the national reference centre between 2009 and 2013 [33-37]. From 2011 to 2013, the total reported number of IPD cases in children $<5$ years of age was stable, with 14 reported cases per year (compared with 22 cases each in 2009 and 2010). PCV10 and PCV13 serotypes comprised 41 and $73 \%$, respectively, of all IPD cases in 2009 and 71 and $93 \%$, respectively, of IPD cases in 2013 (Table 2). In adults $>50$ years of age, PCV10 and PCV13 serotypes accounted for 37 and $69 \%$, respectively, of all IPD cases in 2009 and 25 and $59 \%$, respectively, of IPD cases in 2013 (Table 3). From 2009, serotype 3 was the most prevalent serotype for IPD in all ages, fluctuating from 16 to $22 \%$ of all cases. Other common serotypes were 14, 19A and 7 F. In 2013, 88 \% of IPD cases caused by serotype 3 occurred in individuals $>50$ years of age while only one case was reported in children $<5$ years of age. Serotype 14 accounted for $7-11 \%$ of all IPD cases between 2009 and 2013. Serotype 19A comprised $3 \%$ of all IPD cases in 2009, increasing to 6-7 \% in 2010-2013.

\section{Finland}

PCV10 was the first PCV in Finland, introduced in September 2010 with a $2+1$ schedule. Vaccine coverage was estimated as $95 \%$ in 2012-2013 [38].

From 2004 to 2010, the incidence of IPD in children $<1$ year of age ranged from 50 to $69 / 100,000$ population and from 27 to $37 / 100,000$ population in those $>64$ years of age. In children $<1$ year of age, the incidence/100,000 population gradually decreased after the introduction of PCV10 to 50.7 in 2010 and 11.2 in 2014. From 2010 to 2014, the overall IPD incidence in adults $>64$ years of age remained unchanged at $30-33 / 100,000$ population due to an increase in nonPCV10-serotype IPD despite a significant reduction in PCV10-serotype IPD in all ages (Table 1) [39].

In children $<5$ years of age, PCV10 and PCV13 serotypes accounted for 84 and $92 \%$, respectively, of all IPD isolates in 2010. By 2014, PCV10 serotypes decreased significantly and accounted for $19 \%$ of all IPD isolates reported. 
However, although the number of isolates was small, the three additional serotypes included in PCV13 increased, representing $51 \%$ all isolates. The most prevalent serotypes in 2014 were 19A (30\%), and 3 (19\%) (Table 2). In adults $>65$ years of age, PCV10 and PCV13 serotypes accounted for 55 and $72 \%$, respectively, of all IPD isolates in 2010. By 2014, PCV10 serotypes had significantly decreased and accounted for $26 \%$ of all isolates while the three additional serotypes included in PCV13 increased, comprising $34 \%$ of all isolates (Table 3 ). The most prevalent serotypes in 2010 were 14 (15\%), 3 (10\%), $23 \mathrm{~F}$ (8\%); in 2014 these were 3 (17\%), $22 \mathrm{~F}$ (12\%) and 19A (11\%). Serotypes 3 and 19A have increased gradually over the last 5 years (2010-2014) with significant numbers of cases occurring in older age groups (>50 years of age) [39].

\section{The Netherlands}

PCV7 was introduced into the NIP in June 2006 with a $3+1$ schedule and it was replaced by PCV10 in April 2011. In November 2013, vaccine schedule was reduced to $2+1$ [40]. Vaccine coverage was high with $\geq 94 \%$ of infants born between April 2006 and 2008 receiving full vaccination by the age of 2 years [41].

Introduction of PCV7 into NIP in 2006 led to a major decrease in IPD due to PCV7 serotypes vaccine-type from 7.4 per 100,000 per year in 2004-2006 to less than 1 per 100,000 per year in 2012-2014 [40]. According to data from nine sentinel laboratories, in 2006, PCV7 serotypes accounted for $48 \%$ of all reported blood isolates, which reduced substantially to $17 \%$ in 2010 and further decreased to $7 \%$ in 2013. In 2010, PCV10 and PCV13 serotypes accounted for 42 and $60 \%$ of all IPD isolates, and the most prevalent serotypes were $7 \mathrm{~F}, 8,19 \mathrm{~A}$ and 1, comprising $46 \%$ of all IPD isolates (Table 3). Two years after PCV10 was introduced into the NIP, these serotypes remained the most prevalent: of all isolates, $17 \%$ were serotype $8,12 \%$ were serotype 7 F, $10 \%$ were serotype 19A and $8 \%$ were serotype 3 . The proportion of PCV10-serotype IPD isolates reduced to $28 \%$ and the proportion of IPD isolates containing the three additional serotypes included in PCV13 remained the same (17\%). Since 2009, serotypes 8, 12 F, 19A, 3, 22 F have gradually increased. No substantial change in prevalence was observed for serotypes $7 \mathrm{~F}$ and 5 [41].

\section{Countries in which both, PCV13 and PCV10 are used Germany}

PCV7 was introduced in July 2006 as part of the NIP with a $3+1$ schedule and was replaced by higher-valent vaccines (PCV10 and PCV13) in 2009. Vaccine coverage was estimated at about $98 \%$ for the first dose but only $64 \%$ for the booster dose in 2014 and PCV 13 was predominantly used with $>90 \%$ market share [42].
The overall incidence of pneumococcal meningitis decreased significantly in children $<16$ years of age from 1.5 to $0.9 / 100,000$ population between 1997-2001 and 2010, respectively, with a further reduction to $0.7 /$ 100,000 population in 2012 . This was driven by the reduction in the incidence of pneumococcal meningitis in children <2 years of age, from 7.7 (1997-2001) to 4.1 (2010) and 3.7/100,000 population (2012). A substantial reduction was observed in non-meningitis IPD, most importantly in children $<2$ years of age (Table 1 ) $[42,43]$.

In children $<16$ years of age among pneumococcal meningitis, PCV7 serotypes accounted for $65 \%$ in 2005-2006 and reduced to zero in 2012-2013. PCV13 serotypes accounted for $83 \%$ in 2005-2006, $56 \%$ in 2008-2009 and reduced to $12 \%$ in 2012-2013. Similar trend was observed in adults $>16$ years of age for PCV13 serotypes IPD: $68 \%$ in 2005-2006, $56 \%$ in 2009-2010 and $25 \%$ in 2012-2013 (Tables 2 and 3) [44].

In children $<16$ years of age, the most prevalent serotypes were 14 and $18 \mathrm{C}$ in pre-PCV7 period, $7 \mathrm{~F}, 18 \mathrm{C}$ and 1 in post-PCV7 period and 7 F, 19A and 10A in 2010-2013. In the adult population ( $>16$ years of age), the most prevalent serotypes during 1992-2006 were 23B and 14. During 2007-2009, serotypes 3 and $7 \mathrm{~F}$ accounted for 13 and $7 \%$, respectively, of all IPD cases, and in 2010-2013, after the introduction of higher-valent PCVs, serotypes 7 F, 23B and 3 accounted for $27 \%$ of all IPD cases (Table 3). PCV13serotype IPD significantly reduced while a diversity of nonPCV13 serotypes emerged in some age groups. Compared with the period following the introduction of $\mathrm{PCV} 7$, serotype 3 increased in children, albeit in very small numbers, and decreased in adults $>16$ years of age. A significant increase in serotype $23 \mathrm{~B}$ was observed for all ages [42, 44].

\section{Sweden}

PCV7 was introduced in January 2009 as part of the NIP with a $2+1$ schedule and was replaced by higher-valent vaccines (PCV10 and PCV13) in 2010. Both higher-valent PCVs are currently used in the immunization programmes of different Swedish counties. PCV coverage in children $<2$ years of age was $98 \%$ in 2012 and 2013 [45].

The overall IPD incidence ranged from 14.4 to 19.5 / 100,000 population during 2005-2011. Compared with the average IPD incidence in 2005-2007, incidence in 2012 decreased by $75 \%$ and $57 \%$ in children aged $<2$ years and 2-4 years of age, respectively. Among adults, no major changes were observed. In 2008, PCV7 serotypes accounted for $68 \%$ of all IPD cases in children $<2$ years of age and this gradually decreased to $12 \%$ in 2012. In 2009 (before the introduction of higher-valent PCVs), PCV13 serotypes accounted for $84 \%$ of all IPD cases in children <2 years, which reduced to $47 \%$ in 2012 (Table 2). In addition, there was a reduction in the proportion of IPD caused by PCV13 in all age groups 
(74. \% in 2009 to $48 \%$ in 2012). Serotypes 22 F, 7 F, 3 and 19A were the most common serotypes in 2011 and 2012. Serotypes 33 F and 11 became important in 2012 [45].

\section{Spain (Catalonia, Navarra)}

In Catalonia and Navarra, PCV7 became available in 2001 in the private market with a $3+1$ schedule. PCV13 and PCV10 became available in 2010. Vaccine uptake was around 50 \% in Catalonia and 78 \% in Navarra in 2013. PCV13 was the most commonly used vaccine $[46,47]$.

In Catalonia, PCV7 serotypes accounted for $21 \%$ of IPD cases in 2005, which reduced to $13 \%$ in 2009. 19A was the most prevalent serotype followed by 14 and 1 in children $<2$ years of age. Serotype 1 was the most prevalent serotype followed by 19A in children 2-4 years of age. During 2005-2009, the most common serotypes in adults $>65$ years of age were $1,3,19 \mathrm{~A}$ and 14 [46].

During 2001-2003 in Navarra, the overall incidence of IPD was highest with $87.1 / 100,000$ population in children $<5$ years and 33.6 in adults $\geq 65$ years of age. It was significantly reduced to $18.7 / 100,000$ in children $<5$ years of age and 25.0/100,000 in adults $\geq 65$ years of age in 2010-2013. The reduction was driven by PCV7 and PCV13 serotypes, particularly in children $<5$ years of age. The incidence of PCV7-serotype IPD decreased from 42.9 to $0.7 / 100,000$ population and that of additional PCV13-serotype IPD from 37.7 to $8.6 / 100,000$ population from 2001-2003 to 2010-2013 (Table 1). During 2004-2009, PCV7- and PCV13-serotypes accounted for 9 and $78 \%$ respectively, of all IPD cases in children $<5$ years of age and 19 and $72 \%$, respectively, of cases in those $\geq 5$ years of age. The most predominant serotype was 19A, which reduced from 32 to $24 \%$ following the use of PCV13 in children $<5$ years of age. The decrease was less prominent in those $\geq 5$ years of age, from $14 \%$ (PCV7 serotypes) to $11 \%$ (PCV13 serotypes). Serotypes 19A, 3 and $7 \mathrm{~F}$ remained important from 2010-2013 [47].

\section{Portugal}

PCV7 became available in Portugal in 2001 in the private market with $3+1$ schedule. Vaccine coverage was $75 \%$ in 2008. In 2009 and 2010 PCV10 and PCV13, respectively, were made available and by 2010 , PCV13 was the most commonly used vaccine $[48,49]$.

A decline in the overall proportion of PCV7-serotype IPD cases in children since 2002 has been observed. PCV7 serotypes accounted for $56 \%$ of infections in 1999-2002 and decreased to $17 \%$ in 2006-2008 [49]. Following the use of higher-valent PCVs in 2010, the incidence of overall IPD decreased in children, particularly in young children, from 52.1 (2008-2009) to 25.1/100,000 population (2011-2012) in children $<1$ year of age and from 31.6 (2008-2009) to $16.1 / 100,000$ population (2011-2012) in children 1-2 years of age. These decreases were driven by reductions in PCV13-serotype IPD, from 43.6 (2008-2009) to $14.8 / 100,000$ population (2011-2012) in children $<1$ year of age and from 28.0 to $9.1 / 100,000$ population in children 1-2 years of age (Table 1) [48].

During 2006-2008, the most common isolates in children were 1 (24\%), 19A (20 \%), 7 F (12\%), 14 (7 \%) and $3(6 \%)$. Serotype 1 was associated with cases of empyema and occurred more often in older children and $19 \mathrm{~A}$ occurred in younger children $(<2$ years of age) [49]. In 2008-2009, the most prevalent serotypes in children under 18 years of age remained the same: 1 and 19A followed by $7 \mathrm{~F}$ and 14, which decreased substantially in 2011-2012. Non-vaccine serotypes, notably 10A, increased in children.

In the adult population in 2008, PCV7-serotype IPD significantly decreased, accompanied by a significant increase in serotypes 1, $7 \mathrm{~F}$ and 19A. PCV13 serotypes accounted for $70 \%$ of all IPD cases in 2008 and decreased to $54 \%$ in 2011 which was mainly driven by decrease in prevalence of serotype 1 and 5. In 2009-2011, the most predominant serotypes were 3 (13\% of all isolates) followed by 7 F, 19A, 14, 1 and 8 [50].

\section{Conclusion}

The epidemiology of pneumococcal diseases has significantly changed with the implementation of routine childhood pneumococcal vaccination programmes in Western Europe. The overall incidence of IPD has decreased (Table 1), mainly driven by significant decreases of vaccine-type IPD in individuals of vaccine-eligible age as well as decreases in older individuals not eligible for pneumococcal vaccination in countries with high vaccine coverage. After 7-10 years of PCV7 use, the incidence of PCV7-serotype IPD became very low in all ages with virtual elimination in children, particularly in countries with high vaccine coverage, such as Belgium, Denmark, France, Norway and the UK $[4,5,11,14,20,25,31]$. Non-PCV7 serotypes became more frequent, particularly 19A, 7 F, 3 and 1 some years after the introduction of PCV7 $[4,5]$.

With the introduction of higher-valent vaccines, a rapid and significant reduction of additional serotypes included in these vaccines was consistently observed. In countries that used PCV13, the proportion of PCV13-preventable IPD cases in children $<5$ years of age declined significantly from $61-73 \%$ in the period after the introduction of PCV7 to $15-53 \%$ in the period after the introduction of PCV13 (Table 2). This was mainly driven by a significant and rapid decline of serotypes 19A, 7 F, 1 and 6A in both vaccine-eligible ages and older age groups (indirect effect). However, despite significant direct and indirect protection, vaccine serotypes such as 19A, $7 \mathrm{~F}$ and 3 were still circulating and prevalent in children. These serotypes were particularly important in older age groups. The extent of reduction of vaccine serotypes in older population (indirect 
effect) was lesser in the early period after the introduction of PCV13 compared with later periods and in countries with lower paediatric vaccine uptake. After 1-2 years after introduction in France, Norway and Switzerland, PCV13 serotypes accounted for $42-62 \%$ of all IPD while only $21 \%$ in the UK at 4 years after PCV13 introduction (Table 3).

In countries that used PCV10, the proportion of PCV13-preventable IPD cases remained high (70-86 \% in vaccine-eligible ages), with a predominance of serotype $19 \mathrm{~A}$ and 3 (Table 2). While some post-marketing case control and cohort-based studies have suggested potential cross-protection of PCV10 against 19A IPD in young children [38, 51, 52], a decrease in IPD caused by serotype $19 \mathrm{~A}$ in older children and in adult populations was not observed. In fact, serotype 19A became significantly and increasingly prevalent, particularly in older age groups in Finland, the Netherlands and Austria (Table 3). A similar trend was observed in New Zealand [53]. In children, the incidence of serotype 3 was very low and reported numbers remained unchanged in most countries. A case-control study in the UK suggested that the effectiveness of PCV13 for serotype 3 in all age groups was non-significant [54]. However, a case-control study in the US $(3+1$ schedule) had described a significant vaccine effectiveness of $76 \%$ (95\% CI 13; 93) against serotype 3 [55] and relevant decreases in serotype 3 IPD were observed in larger observational studies in the UK and France [20, 31].

Serotype diversity generally increased, with diverse serotypes emerging depending on the country, time from introduction of higher-valent PCVs and the types of vaccine used. However, newly emerging non-PCV13 vaccine types were shown to be less invasive with low case-carrier ratio $[56,57]$ and no individual serotype has emerged in the same way as serotypes 19A and $7 \mathrm{~F}$ emerged after the introduction of PCV7. To date, serotypes 24 F, 22 F, 8 and 15A are becoming important in countries that use PCV13 and serotypes 19A and 3 in countries that use PCV10. In this review, otitis media and pneumococcal pneumonia and related serotypes were not discussed, despite the fact that the public health value of pneumococcal vaccination is largely based on the these diseases. However, given the diagnostic and ethical problems to obtain appropriate cultures for testing, the serotype epidemiology of non-invasive diseases is largely unknown. In this respect, nasopharyngeal carriage studies may serve as a surrogate to monitor the serotype evolution in non-invasive diseases, as mucosal pneumococcal diseases results from direct infection.

The knowledge of emerging vaccine serotypes is important to continuously monitor the risk-benefit profile of PCVs. The data presented here are also needed to develop next generation pneumococcal vaccines.

\section{Abbreviations}

IPD: Invasive pneumococcal disease; PCV: Pneumococcal conjugate vaccine; PCV7: 7-valent pneumococcal conjugate vaccine; PCV13: 13-valent pneumococcal conjugate vaccine; NIP: National immunization programme.

\section{Competing interests}

H-JS, DC and this should read MTTH are employees of Pfizer Vaccines, France and hold shares in Pfizer.

\section{Authors' contributions}

DC and this should read MTTH collated surveillance data based on literature search. H-JS, DC and TTHM contributed to the writing of the manuscript. All authors commented on all drafts and approved the final version of the manuscript.

\section{Authors' information}

Not applicable.

\section{Acknowledgements}

The authors take full responsibility for the content of this article and thank Neostar Communications Ltd., Oxford, UK (funded by Pfizer, Paris, France) for their assistance in preparing the manuscript, including preparing the first draft in close collaboration with the authors and the collation of author comments.

Received: 7 August 2015 Accepted: 24 September 2015

Published online: 14 October 2015

\section{References}

1. WHO Publication. Pneumococcal vaccines WHO position paper - 2012 recommendations. Vaccine. 2012;30(32):4717-8.

2. Weil-Olivier C, van der Linden M, de Schutter I, Dagan R, Mantovani L. Prevention of pneumococcal diseases in the post-seven valent vaccine era: a European perspective. BMC Infect Dis. 2012;12:207.

3. Tin Tin Htar M, Madhava H, Balmer P, Christopoulou D, Menegas D, Bonnet E. A review of the impact of pneumococcal polysaccharide conjugate vaccine (7-valent) on pneumococcal meningitis. Adv Ther. 2013;30(8):748-62.

4. Myint TT, Madhava H, Balmer P, Christopoulou D, Attal S, Menegas D, et al. The impact of 7-valent pneumococcal conjugate vaccine on invasive pneumococcal disease: a literature review. Adv Ther. 2013;30(2):127-51.

5. Fitzwater SP, Chandran A, Santosham M, Johnson HL. The worldwide impact of the seven-valent pneumococcal conjugate vaccine. Pediatr Infect Dis J. 2012;31(5):501-8.

6. Feikin DR, Kagucia EW, Loo JD, Link-Gelles R, Puhan MA, Cherian T, et al. Serotype-specific changes in invasive pneumococcal disease after pneumococcal conjugate vaccine introduction: a pooled analysis of multiple surveillance sites. PLoS Med. 2013;10(9):e1001517.

7. Ben-Shimol S, Givon-Lavi N, Leibovitz E, Raiz S, Greenberg D, Dagan R. Near-elimination of otitis media caused by 13-valent pneumococcal conjugate vaccine (PCV) serotypes in southern Israel shortly after sequential introduction of 7-valent/13-valent PCV. Clin Infect Dis. 2014;59(12):1724-32.

8. Griffin MR, Zhu Y, Moore MR, Whitney CG, Grijalva CG. U.S. hospitalizations for pneumonia after a decade of pneumococcal vaccination. N Engl J Med. 2013;369(2):155-63.

9. van Hoek AJ, Sheppard CL, Andrews NJ, Waight PA, Slack MP, Harrison TG, et al. Pneumococcal carriage in children and adults two years after introduction of the thirteen valent pneumococcal conjugate vaccine in England. Vaccine. 2014;32(34):4349-55

10. Miller E, Andrews NJ, Waight PA, Slack MP, George RC. Herd immunity and serotype replacement 4 years after seven-valent pneumococcal conjugate vaccination in England and Wales: an observational cohort study. Lancet Infect Dis. 2011;11(10):760-8.

11. Sabbe MTG, Grammens T, Braeye T, Bleyenheuft C, Quoilin S. Maladies infectieuses pédiatriques àprévention vaccinale, Rapport Annuel 2013. Bruxelles: Institut scientifique de Santé publique (WIV-ISP); 2015. p. 156.

12. Liesenborghs L, Verhaegen J, Peetermans WE, Vandeven J, Flamaing J. Trends in serotype prevalence in invasive pneumococcal disease before and after infant pneumococcal vaccination in Belgium, 2002-2010. Vaccine. 2013;31(11):1529-34.

13. Statens Serum Institute. Invasive pneumococcal disease and PCV coverage 2012. In: EPI-NEWS. 2013. 
14. Harboe ZB, Dalby T, Weinberger DM, Benfield T, Molbak K, Slotved HC, et al. Impact of 13-valent pneumococcal conjugate vaccination in invasive pneumococcal disease incidence and mortality. Clin Infect Dis. 2014;59(8):1066-73.

15. Slotved HC, Dalby T, Hoffmann S. Invasive pneumococcal isolates from Danish infants (0-90 Days) during the years 1943 to 2013. PLoS One. 2014;9(8):e106180.

16. Harboe ZB, Valentiner-Branth $\mathrm{P}$, Benfield TL, Christensen JJ, Andersen PH, Howitz $M$, et al. Early effectiveness of heptavalent conjugate pneumococcal vaccination on invasive pneumococcal disease after the introduction in the Danish Childhood Immunization Programme. Vaccine. 2010;28(14):2642-7.

17. Harboe ZB, Valentiner-Branth $\mathrm{P}$, Ingels H, Rasmussen JN, Andersen PH, Bjerre CC, et al. Pediatric invasive pneumococcal disease caused by vaccine serotypes following the introduction of conjugate vaccination in Denmark. PLoS One. 2013;8(1):e51460.

18. Varon E, Janoir C, Gutmann L. Rapport d'activité 2013 Epidémiologie 2012. In: Centre National de Référence des Pneumocoques (CNRP). 2013.

19. Institute de Veille Sanitaire. Pneumocoque. In. http://www.invs.sante.fr/ Dossiers-thematiques/Maladies-infectieuses/Maladies-a-prevention-vaccinale/ Couverture-vaccinale/Donnees/Pneumocoque; 2015. Accessed 5 August 2015.

20. Lepoutre A, Varon E, Georges S, Dorleans F, Janoir C, Gutmann L, et al. Impact of the pneumococcal conjugate vaccines on invasive pneumococcal disease in France, 2001-2012. Vaccine. 2015;33(2):359-66.

21. Health Protection Surveillance Centre. Streptococcus pneumoniae (invasive), Annual Report 2012 In. http://www.hpsc.ie/AboutHPSC/AnnualReports/ File,14421,en.pdf; 2013. Accessed 5 August 2015.

22. Corcoran. M, Humphreys H, Vickers I, O'Flanagan D, Cotter S, Cunney R, et al. Impact of the Pneumococcal Conjugate Vaccines (PCV) on the burden of invasive pneumococcal disease (IPD) in Ireland. In., vol. 2015. http://www.hpsc.ie/A-ZNaccinePreventable/PneumococcalDisease/ PostersPresentations/File,4292,en.pdf; 2015. Accessed 5 August 2015.

23. Azzari C, Moriondo M, Cortimiglia M, Valleriani C, Canessa C, Indolfi G, et al. Potential serotype coverage of three pneumococcal conjugate vaccines against invasive pneumococcal infection in Italian children. Vaccine. 2012;30(16):2701-5.

24. D'Ancona FP CM, Giambi C. Dati di sorveglianza delle malattie batteriche invasive aggiornati al 23 marzo 2015. In. http://www.iss.it/binary/mabi/cont/ Report_MBI_20150323_V8.pdf Centro Nazionale di Epidemiologia, Sorveglianza e Prevenzione della Salute; 2015: 25. Acessed 5 August 2015.

25. Steens A, Bergsaker MA, Aaberge IS, Ronning K, Vestrheim DF. Prompt effect of replacing the 7-valent pneumococcal conjugate vaccine with the 13-valent vaccine on the epidemiology of invasive pneumococcal disease in Norway. Vaccine. 2013:31(52):6232-8.

26. Picazo J, Ruiz-Contreras J, Casado-Flores J, Giangaspro E, Garcia-de-Miguel MJ, Hernandez-Sampelayo T, et al. Impact of introduction of conjugate vaccines in the vaccination schedule on the incidence of pediatric invasive pneumococcal disease requiring hospitalization in Madrid 2007 to 2011. Pediatr Infect Dis J. 2013;32(6):656-61.

27. Picazo J, Ruiz-Contreras J, Casado-Flores J, Negreira S, Garcia-de-Miguel MJ, Hernandez-Sampelayo T, et al. Expansion of serotype coverage in the universal pediatric vaccination calendar: short-term effects on age- and serotype-dependent incidence of invasive pneumococcal clinical presentations in Madrid, Spain. Clin Vaccine Immunol. 2013:20(10):1524-30.

28. Servicio de Epidemiología. Enfermedad Neumococica Invasora Comunidad de Madrid, Edo 2013. In: Servicio Madrileno de Salud. 2014. p. 29.

29. Office Fédéral de la Santé Publique (OFSP). Maladies à pneumocoques 2012. In: Bulletin 4/14: Office Fédéral de la Santé Publique. 2014. p. 41-8.

30. Office Fédéral de la Santé Publique (OFSP). Maladies à pneumocoques 2010-2011. In: Bulletin 9: Office Fédéral de la Santé Publique. 2013. p. 109-17.

31. Waight PA, Andrews NJ, Ladhani SN, Sheppard CL, Slack MP, Miller E. Effect of the 13-valent pneumococcal conjugate vaccine on invasive pneumococcal disease in England and Wales 4 years after its introduction: an observational cohort study. Lancet Infect Dis. 2015;15(5):535-43.

32. Paulke-Korinek M, Kollaritsch H, Kundi M, Schmidle-Loss B, Zwazl I, Laaber B, et al. Characteristics of invasive pneumococcal disease in hospitalized children in Austria. Eur J Pediatr. 2014;173(4):469-76.

33. Sigrid Heuberger UO. Nationale Referenzzentrale für Pneumokokken. In: Institut für medizinische Mikrobiologie. 2010. p. 12.

34. Sigrid Heuberger GS. Nationale Referenzzentrale für Pneumokokken Jahresbericht 2011. In: Institut für medizinische Mikrobiologie. 2012. p. 15.
35. Sigrid Heuberger UO. Nationale Referenzzentrale für Pneumokokken Jahresbericht 2010. In: Institut für medizinische Mikrobiologie. 2011. p. 19.

36. Georg Steindl SH. Nationale Referenzzentrale für Pneumokokken Jahresbericht 2012. In: Institut für medizinische Mikrobiologie. 2013. p. 12.

37. Georg Steindl CK, Schmid D. Nationale Referenzzentrale für Pneumokokken Jahresbericht 2013. In: Institut für medizinische Mikrobiologie. 2014. p. 13.

38. Jokinen J, Rinta-Kokko H, Siira L, Palmu AA, Virtanen MJ, Nohynek H, et al. Impact of ten-valent pneumococcal conjugate vaccination on invasive pneumococcal disease in Finnish children-a population-based study. PLoS One. 2015;10(3):e0120290.

39. National Institute for Health and Welfare Finland. Incidence of invasive pneumococcal disease in Finland. In. https://www.thl.fi/en/web/thlfi-en/topics/ information-packages/incidence-of-invasive-pneumococcal-disease-in-finland; 2015. Accessed 5 August 2015.

40. National Institute for Public Health and the Environment. The National Immunisation Programme in the Netherlands Surveillance and developments in 2013-2014. In. http://www.rivm.nl/ dsresource?objectid=rivmp:264894\&type=org\&disposition=inline; 2014: 152. Accessed 5 August 2015.

41. Netherlands Reference Laboratory for Bacterial Meningitis (AMC/RIVM). Bacterial meningitis in the Netherlands; annual report 2013. In. https:/www.amc.nl/web/ Research/Overview/Departments/Medical-Microbiology/Medical-Microbiology/ Current-research/Reference-Laboratory-for-Bacterial-Meningitis.htm?print=true; 2014: 61. Accessed 5 August 2015.

42. Weiss S, Falkenhorst $G$, van der Linden M, Imohl M, von Kries R. Impact of 10- and 13-valent pneumococcal conjugate vaccines on incidence of invasive pneumococcal disease in children aged under 16 years in Germany, 2009 to 2012. Euro Surveill. 2015;20(10):21057.

43. van der Linden M, Weiss S, Falkenhorst G, Siedler A, Imohl M, von Kries R. Four years of universal pneumococcal conjugate infant vaccination in Germany: impact on incidence of invasive pneumococcal disease and serotype distribution in children. Vaccine. 2012;30(40):5880-5.

44. Imohl M, Moller J, Reinert RR, Perniciaro S, van der Linden M, Aktas O. Pneumococcal meningitis and vaccine effects in the era of conjugate vaccination: results of 20 years of nationwide surveillance in Germany. BMC Infect Dis. 2015;15(1):61.

45. Smittskyddsinstitutet. Vaccinationsstatistik från barnavårdscentralerna 2013, gällande barn födda 2010. In. http://www.folkhalsomyndigheten.se/ documents/smittskydd-sjukdomar/vaccinationer/vaccinationsstatistik-franbarnavardscentralerna-2013-sverige.pdf; 2013. Accessed 5 August 2015.

46. Ciruela P, Martinez A, Izquierdo C, Hernandez S, Broner S, Munoz-Almagro C, et al. Epidemiology of vaccine-preventable invasive diseases in Catalonia in the era of conjugate vaccines. Hum Vaccin Immunother. 2013;9(3):681-91.

47. Guevara M, Ezpeleta C, Gil-Setas A, Torroba L, Beristain X, Aguinaga A, et al. Reduced incidence of invasive pneumococcal disease after introduction of the 13-valent conjugate vaccine in Navarre, Spain, 2001-2013. Vaccine. 2014;32(22):2553-62.

48. Aguiar SI, Brito MJ, Horacio AN, Lopes JP, Ramirez M, Melo-Cristino J, et al. Decreasing incidence and changes in serotype distribution of invasive pneumococcal disease in persons aged under 18 years since introduction of 10-valent and 13-valent conjugate vaccines in Portugal, July 2008 to June 2012. Euro Surveill. 2014;19(12):20750.

49. Aguiar SI, Brito MJ, Goncalo-Marques J, Melo-Cristino J, Ramirez M. Serotypes 1, $7 \mathrm{~F}$ and 19A became the leading causes of pediatric invasive pneumococcal infections in Portugal after 7 years of heptavalent conjugate vaccine use. Vaccine. 2010;28(32):5167-73.

50. Horacio AN, Diamantino-Miranda J, Aguiar SI, Ramirez M, Melo-Cristino J, Portuguese Group for the Study of Streptococcal I. The majority of adult pneumococcal invasive infections in Portugal are still potentially vaccine preventable in spite of significant declines of serotypes 1 and 5. PLoS One. 2013;8(9):e73704

51. Deceuninck G, De Serres G, Boulianne N, Lefebvre B, De Wals P. Effectiveness of three pneumococcal conjugate vaccines to prevent invasive pneumococcal disease in Quebec, Canada. Vaccine. 2015;33(23):2684-9.

52. Domingues CM, Verani JR, Montenegro Renoiner El, de Cunto Brandileone MC, Flannery B, de Oliveira LH, et al. Effectiveness of ten-valent pneumococcal conjugate vaccine against invasive pneumococcal disease in Brazil: a matched case-control study. Lancet Respir Med. 2014;2(6):464-71.

53. Institute of Environmental Science and Research. Invasive pneumococcal disease in New Zealand 2013. In. https://surv.esr.cri.nz/PDF_surveillance/IPD/ 2013/2013AnnuallPDRpt.pdf; 2014: 75. Accessed 5 August 2015. 
54. Andrews NJ, Waight PA, Burbidge P, Pearce E, Roalfe L, Zancolli M, et al. Serotype-specific effectiveness and correlates of protection for the 13-valent pneumococcal conjugate vaccine: a postlicensure indirect cohort study. Lancet Infect Dis. 2014;14(9):839-46.

55. Moore M. Update on PCV13 effectiveness and herd effects in the U.S, Summary Report February 26-27, 2014. Atlanta, Georgia: Advisory Committee on Immunization Practices (ACIP); 2014.

56. Flasche S, Le Polain de Waroux O, O'Brien KL, Edmunds WJ. The serotype distribution among healthy carriers before vaccination is essential for predicting the impact of pneumococcal conjugate vaccine on invasive disease. PLoS Comput Biol. 2015;11(4):e1004173.

57. Steens A, Caugant DA, Aaberge IS, Vestrheim DF. Decreased Carriage and Genetic Shifts in the Streptococcus pneumoniae Population After Changing the 7-Valent to the 13-Valent Pneumococcal Vaccine in Norway. Pediatr Infect Dis J. 2015:34:875.

\section{Submit your next manuscript to BioMed Central and take full advantage of:}

- Convenient online submission

- Thorough peer review

- No space constraints or color figure charges

- Immediate publication on acceptance

- Inclusion in PubMed, CAS, Scopus and Google Scholar

- Research which is freely available for redistribution 